Buletin Ilmiah Math. Stat. dan Terapannya (Bimaster)

Volume 08, No. 4 (2019), hal 737 - 744.

\title{
METODE FULL ORTHOGONALIZATION UNTUK MENYELESAIKAN SISTEM PERSAMAAN LINEAR
}

\author{
Sepliong, Yundari, Fransiskus Fran
}

\section{INTISARI}

\begin{abstract}
Sistem persamaan linear dapat diselesaikan dengan metode langsung dan metode iteratif. Salah satu metode iteratif untuk menyelesaikan sistem persamaan linear yaitu metode Full Orthogonalization.. Penyelesaian sistem persamaan linear dengan metode Full Orthogonalization dapat dilakukan dengan cara mereduksi matriks A yang merupakan matriks koefisien dari sistem persamaan linear menjadi matriks Hessenberg $\mathbf{H}_{\mathrm{m}}$ dengan menggunakan algoritma Arnoldi. Matriks $\mathbf{A}$ dapat ditulis sebagai $\mathbf{A}=\mathbf{V}_{m} \mathbf{H}_{m} \mathbf{V}_{m}^{T}$ dengan $\mathbf{V}_{m}$ matriks ortogonal. Setelah diperoleh matriks Hessenberg $\mathbf{H}_{m}$, selanjutnya ditentukan invers dari matriks Hessenberg dengan eliminasi Gauss-Jordan. Langkah selanjutnya setelah invers matriks Hessenberg diperoleh yaitu mencari vektor $\boldsymbol{y}_{m}$. Solusi pendekatan sistem persamaan linear dicari dengan rumus $\mathbf{x}_{m}=\mathbf{x}_{0}+\mathbf{V}_{m} \mathbf{y}_{m}$.
\end{abstract}

Kata Kunci : sistem persamaan linear, algoritma Arnoldi, ortogonal.

\section{PENDAHULUAN}

Matematika merupakan salah satu bidang ilmu yang sangat berperan dalam kehidupan sehari-hari. Banyak permasalahan dalam kehidupan sehari-hari yang akan lebih mudah diselesaikan jika dibawa ke dalam model matematika. Selain itu, banyak bidang ilmu lain yang dalam perkembangannya sangat bergantung pada metematika seperti, fisika, ekonomi, kimia dan lain-lain [1]. Ilmu matematika sendiri terdiri dari beberapa kajian. Salah satu kajian dalam matematika adalah aljabar linear yang diantaranya mempelajari tentang sistem persamaan linear (SPL) dan matriks. Suatu persamaan linear dalam $n$ variabel $x_{1}, x_{2}, \ldots, x_{n}$ adalah suatu persamaan dalam bentuk $a_{1} x_{1}+a_{2} x_{2}+\cdots+a_{n} x_{n}=b$, dengan $a_{i}, i=1,2,3, \ldots, n$ dan $b$ merupakan konstanta real. Sejumlah persamaan linear yang banyaknya berhingga disebut sistem persamaan linear [1].

Secara umum penyelesaian sistem persamaan linear dapat diselesaikan dengan metode langsung dan metode iteratif. Metode langsung diantaranya metode eliminasi Gauss, eliminasi Gauss-Jordan dan aturan Cramer. Metode langsung tidak efisien apabila digunakan untuk menyelesaikan sistem persamaan linear dengan ukuran besar. Sebaliknya, metode iteratif lebih efisien bila digunakan untuk menyelesaikan sistem persamaan linear yang berukuran besar. Salah satu metode iteratif untuk menyelesaikan sistem persamaan linear yaitu metode Full Orthogonalization [2].

Metode Full Orthogonalization merupakan salah satu jenis metode subruang Krylov yang menggunakan algoritma Arnoldi. Subruang Krylov, diperkenalkan oleh Alexei Nikolaevic Krylov seorang matematikawan berkebangsaan Rusia yang digunakan pertama kali untuk mencari polinomial karakteristik dari suatu matriks [3]. Algoritma Arnoldi pertama kali diperkenalkan oleh Walter Edwin Arnoldi, yaitu seorang ilmuan berkebangsaan Amerika. Algoritma Arnoldi digunakan untuk mereduksi sebarang matriks real menjadi matriks Hessenberg yang lebih sederhana [3]. Dalam perkembangannya algoritma Arnoldi dikombinasikan dengan subruang Krylov untuk menyelesaikan sistem persamaan linear. Kombinasi tersebut dinamakan metode Full Orthogonalization. Oleh karena itu, pada penelitian ini akan diterapkan metode Full Orthogonalization untuk menyelesaikan sistem persamaan linear. Masalah yang dibahas pada penelitian ini dibatasi pada sistem persamaan linear 
taksingular.

Metodologi penelitian ini diawali dengan diberikan sistem persamaan linear dengan matriks koefisien taksingular. Matriks koefisien tersebut direduksi menggunakan algoritma Arnoldi sehingga diperoleh matriks Hessenberg dan matriks ortogonal yang terdiri dari vektor-vektor kolom yang merupakan basis untuk subruang Krylov. Kemudian ditentukan invers dari matriks Hessenberg dengan menggunakan eliminasi Gauss-Jordan. Langkah selanjutnya, ditentukan vektor $\mathbf{y}_{m}$. Solusi pendekatan sistem persamaan linear dicari dengan rumus $\mathbf{x}_{m}=\mathbf{x}_{0}+\mathbf{V}_{m} \mathbf{y}_{m}$.

\section{SUBRUANG KRYLOV}

Berikut ini diberikan definisi mengenai subruang Krylov.

Definisi 1 [3] Diberikan matriks A berukuran $n \times n$. Matriks

$$
\mathbf{K}_{m}(\mathbf{A}, \mathbf{v}):=\left[\begin{array}{lllll}
\mathbf{v} & \mathbf{A v} & \mathbf{A}^{\mathbf{2}} \mathbf{v} & \ldots & \mathbf{A}^{m-1} \mathbf{v}
\end{array}\right] \in \mathbb{R}^{n \times m}
$$

dibangun oleh vektor $\mathbf{v} \in \mathbb{R}^{n}$ disebut matriks Krylov. Kolom-kolom dari matriks Krylov membangun subruang, yaitu:

yang disebut subruang Krylov.

$$
\mathcal{K}_{m}(\mathbf{A}, \mathbf{v}):=\operatorname{span}\left\{\mathbf{v}, \mathbf{A} \mathbf{v}, \mathbf{A}^{2} \mathbf{v}, \ldots, \mathbf{A}^{m-1} \mathbf{v}\right\}
$$

Contoh 2 Diberikan matriks $\mathbf{A}=\left[\begin{array}{lll}1 & 1 & 3 \\ 4 & 3 & 2 \\ 3 & 6 & 1\end{array}\right]$ dan vektor tak nol $\mathbf{v}=\left[\begin{array}{l}1 \\ 3 \\ 2\end{array}\right]$. Matriks $\mathbf{A}$ dan vektor $\mathbf{v}$ membangun matriks Krylov

$$
\begin{aligned}
& \mathbf{K}_{3}(\mathbf{A}, \mathbf{v})=\left[\mathbf{v} A \mathbf{v} A^{2} \mathbf{v}\right] \\
& =\left[\begin{array}{ccc}
1 & 10 & 96 \\
3 & 17 & 137 \\
2 & 23 & 155
\end{array}\right] .
\end{aligned}
$$

Kolom-kolom dari matriks $\mathbf{K}_{3}(\mathbf{A}, \mathbf{v})$ membangun suatu subruang Krylov, yaitu

$$
\mathcal{K}_{3}=\operatorname{span}\left\{\mathbf{v}, \mathbf{A v}, \mathbf{A}^{2} \mathbf{v}\right\}=\operatorname{span}\left\{\left[\begin{array}{l}
1 \\
3 \\
2
\end{array}\right],\left[\begin{array}{l}
10 \\
17 \\
23
\end{array}\right],\left[\begin{array}{c}
96 \\
137 \\
155
\end{array}\right]\right\} .
$$

Definisi 3 [4] Diberikan A adalah sebarang matriks berukuran $n \times n$. Polinomial minimal dari $\mathbf{v}$ adalah polinomial monik $p$ dengan derajat terkecil sehingga $p(\mathbf{A}) \mathbf{v}=0$.

Contoh 4 Diberikan matriks $\mathbf{A}=\left[\begin{array}{lll}0 & 1 & 0 \\ 0 & 0 & 1 \\ 0 & 0 & 0\end{array}\right]$ dan vektor $\mathbf{v}=\left[\begin{array}{l}1 \\ 2 \\ 3\end{array}\right]$. Polinomial $p(x)=x^{3}$ adalah polinomial minimal dari $\mathbf{v}$, karena, $p(\mathbf{A}) \mathbf{v}=\left[\begin{array}{lll}0 & 1 & 0 \\ 0 & 0 & 1 \\ 0 & 0 & 0\end{array}\right]^{3}\left[\begin{array}{l}1 \\ 2 \\ 3\end{array}\right]=\left[\begin{array}{l}0 \\ 0 \\ 0\end{array}\right]$.

Beberapa sifat dari subruang Krylov dapat dilihat pada proposisi 5, 6 dan 7.

Proposisi 5 [3] Subruang Krylov $\mathcal{K}_{m}$ adalah subruang dari semua vektor-vektor dalam $\mathbb{R}^{n}$ yang dapat ditulis sebagai $\mathbf{x}=p(\mathbf{A}) \mathbf{v}$, dimana $p(\mathbf{A})$ polinomial dengan pangkat tidak lebih dari $m-1$.

Proposisi 6 [5] Subruang Krylov $\mathcal{K}_{m}$ memiliki dimensi $m$ jika dan hanya jika derajat polinomial untuk matriks A lebih besar dari $m-1$.

Proposisi 7 [5] Vektor-vektor $\mathbf{v}_{1}, \mathbf{v}_{2}, \ldots, \mathbf{v}_{m}$ adalah basis ortonormal dari subruang Krylov yang direntang oleh $\mathcal{K}_{m}=\operatorname{span}\left\{\mathbf{v}_{1}, \mathbf{v}_{2}, \ldots, \mathbf{v}_{m}\right\}$.

\section{ALGORITMA ARNOLDI}

Algoritma Arnoldi digunakan untuk membangun basis ortogonal dari subruang $\operatorname{Krylov} \mathcal{K}_{m}(\mathbf{A}, \mathbf{v})$. Misalkan matriks A berukuran $n \times n$, maka matriks A dapat dinyatakan sebagai perkalian matriks Hessenberg dan matriks ortogonal, yaitu [2]: 


$$
\mathbf{A}=\mathbf{V}_{m} \mathbf{H}_{m} \mathbf{V}_{m}^{T}
$$

dengan $\mathbf{V}_{m}$ adalah matriks ortogonal $m$ kolom dan $\mathbf{H}_{m}$ adalah matriks Hessenberg $m \times m$, dengan $m \leq n$. Misalkan $\mathbf{V}_{m}$ adalah matriks yang berbentuk,

$$
\mathbf{v}_{m}=\left[\begin{array}{llll}
\mathbf{v}_{1} & \mathbf{v}_{2} & \ldots & \mathbf{v}_{m}
\end{array}\right]
$$

dengan $\mathbf{v}_{i}$ adalah kolom ke- $i$ dari matriks ortogonal $\mathbf{V}_{m}$ yang ortonormal dengan $\mathbf{v}_{j}$ untuk $i \neq j$ dan $\mathbf{H}_{m}$ adalah matriks Hessenberg yang berbentuk,

$$
\mathbf{H}_{m}=\left[\begin{array}{cccccc}
h_{1,1} & h_{1,2} & h_{1,3} & \cdots & h_{1, m-1} & h_{1, m} \\
h_{2,1} & h_{2,2} & h_{2,3} & \cdots & h_{2, m-1} & h_{2, m} \\
0 & h_{3,2} & h_{3,3} & \cdots & h_{3, m-1} & h_{3, m} \\
0 & 0 & h_{4,3} & \cdots & h_{4, m-1} & h_{4, m} \\
\vdots & \vdots & \vdots & \ddots & \vdots & \vdots \\
0 & 0 & 0 & \cdots & h_{m, m-1} & h_{m, m}
\end{array}\right] .
$$

Dengan mengalikan kedua ruas pada Persamaan (1) dengan $\mathbf{V}_{m}$, maka diperoleh

Perkalian dari matriks $\mathbf{A}$ dan $\mathbf{V}_{m}$ adalah

$$
\begin{aligned}
\mathbf{A} \mathbf{V}_{m} & =\mathbf{V}_{m} \mathbf{H}_{m} \mathbf{V}_{m}^{T} \mathbf{V}_{m} \\
\mathbf{A} \mathbf{V}_{m} & =\mathbf{V}_{m} \mathbf{H}_{m} .
\end{aligned}
$$

$$
\begin{aligned}
\mathbf{A} \mathbf{V}_{m} & =\left[\begin{array}{cccc}
a_{1,1} & a_{1,2} & \cdots & a_{1, n} \\
a_{2,1} & a_{2,2} & \cdots & a_{2, n} \\
\vdots & \vdots & \ddots & \vdots \\
a_{n, 1} & a_{n, 2} & \cdots & a_{n, n}
\end{array}\right]\left[\begin{array}{cccc}
v_{1,1} & v_{1,2} & \cdots & v_{1, m} \\
v_{2,1} & v_{2,2} & \cdots & v_{2, m} \\
\vdots & \vdots & \ddots & \vdots \\
v_{n, 1} & v_{n, 2} & \cdots & v_{n, m}
\end{array}\right] \\
& =\left[\begin{array}{cccc}
a_{1,1} v_{1,1}+\cdots+a_{1, n} v_{n, 1} & a_{1,1} v_{1,2}+\cdots+a_{1, n} v_{n, 2} & \cdots & a_{1,1} v_{1, m}+\cdots+a_{1, n} v_{n, m} \\
a_{2,1} v_{1,1}+\cdots+a_{2, n} v_{n, 1} & a_{2,1} v_{1,2}+\cdots+a_{2, n} v_{n, 2} & \cdots & a_{2,1} v_{1, m}+\cdots+a_{2, n} v_{n, m} \\
\vdots & \vdots & \ddots & \vdots \\
a_{n, 1} v_{1,1}+\cdots+a_{n, m} v_{n, 1} & a_{n, 2} v_{1,2}+\cdots+a_{n, n} v_{n, 2} & \cdots & a_{m, 1} v_{1, m}+\cdots+a_{n, n} v_{n, m}
\end{array}\right]
\end{aligned}
$$

dan perkalian dari matriks $\mathbf{V}_{m}$ dan $\mathbf{H}_{m}$

$$
\begin{aligned}
& \mathbf{V}_{m} \mathbf{H}_{m}=\left[\begin{array}{cccccc}
v_{1,1} & v_{1,2} & v_{1,3} & \cdots & v_{1, m-1} & v_{1, m} \\
v_{2,1} & v_{2,2} & v_{2,3} & \cdots & v_{2, m-1} & v_{2, m} \\
v_{3,1} & v_{3,2} & v_{3,3} & \cdots & v_{3, m-1} & v_{3, m} \\
v_{4,1} & v_{4,2} & v_{4,3} & \cdots & v_{4, m-1} & v_{4, m} \\
\vdots & \vdots & \vdots & \ddots & \cdots & \vdots \\
v_{n, 1} & v_{n, 2} & v_{n, 3} & \cdots & v_{n, m-1} & a_{n, m}
\end{array}\right]\left[\begin{array}{cccccc}
h_{1,1} & h_{1,2} & h_{1,3} & \cdots & h_{1, m-1} & h_{1, m} \\
h_{2,1} & h_{2,2} & h_{2,3} & \cdots & h_{2, m-1} & h_{2, m} \\
0 & h_{3,2} & h_{3,3} & \cdots & h_{3, m-1} & h_{3, m} \\
0 & 0 & h_{4,3} & \cdots & h_{4, m-1} & h_{4, m} \\
\vdots & \vdots & \vdots & \ddots & \cdots & \vdots \\
0 & 0 & 0 & \cdots & h_{n, m-1} & h_{m, m}
\end{array}\right] \\
& =\left[\begin{array}{cccc}
v_{1,1} h_{1,1}+v_{1,2} h_{2,1} & v_{1,1} h_{1,2}+v_{1,2} h_{2,2}+v_{1,3} h_{3,2} & \cdots & v_{1,1} h_{1, m}+\cdots+v_{1, m} h_{m, m} \\
v_{2,1} h_{1,1}+v_{2,2} h_{2,1} & v_{2,1} h_{1,2}+v_{2,2} h_{2,2}+v_{2,3} h_{3,2} & \cdots & v_{2,1} h_{1, m}+\cdots+v_{2, m} h_{m, m} \\
\vdots & \vdots & \cdots & \vdots \\
v_{n, 1} h_{1,1}+v_{n, 2} h_{2,1} & v_{n, 1} h_{1,2}+v_{n, 2} h_{2,3}+v_{n, 3} h_{3,2} & \cdots & v_{n, 1} h_{1, m}+\cdots+v_{n, m} h_{m, m}
\end{array}\right] .
\end{aligned}
$$

Diperhatikan kolom ke-j dari hasil perkalian matriks $\mathbf{V}_{m}$ dan $\mathbf{H}_{m}$ diperoleh

$$
\mathbf{A} \mathbf{v}_{\mathbf{j}}=h_{1, j} \mathbf{v}_{1}+h_{2, j} \mathbf{v}_{2}+\cdots+h_{j+1, j} \mathbf{v}_{j+1} .
$$

Persamaan (2) dapat disederhanakan menjadi:

$$
\mathbf{A v}_{j}=\sum_{i=1}^{j+1} h_{i, j} \mathbf{v}_{i}
$$

Selanjutnya, jika kedua ruas pada Persamaan (3) dikalikan dengan $\mathbf{v}_{k}^{T}$ diperoleh,

$$
\begin{aligned}
\mathbf{v}_{k}^{T} \mathbf{A} \mathbf{v}_{j} & =\sum_{i=1}^{j+1} h_{i, j} \mathbf{v}_{i} \mathbf{v}_{k}^{T}, \quad 1 \leq k \leq j \\
\mathbf{v}_{k}^{T} \mathbf{A} \mathbf{v}_{j} & =h_{k, j},
\end{aligned}
$$

sehingga entri dari matriks $\mathbf{H}_{m}$ didefinisikan sebagai, 
Dari Persamaan (3 ) diperoleh,

$$
h_{k, j}=\mathbf{v}_{k}^{T} \mathbf{A} \mathbf{v}_{j}
$$

$$
\mathbf{A} \mathbf{v}_{j}=\sum_{i=1}^{j} h_{i, j} \mathbf{v}_{i}+h_{j+1, j} \mathbf{v}_{j+1}
$$

yang ekuivalen dengan,

$$
h_{j+1, j} \mathbf{v}_{j+1}=\mathbf{A} \mathbf{v}_{j}-\sum_{i=1}^{j} h_{i, j} \mathbf{v}_{i},
$$

sehingga kolom ke- $(j+1)$ dari matriks $\mathbf{V}_{m}$ didefinisikan sebagai

$$
\mathbf{v}_{j+1}=\frac{1}{h_{j+1, j}}\left(\mathbf{A} \mathbf{v}_{j}-\sum_{i=1}^{j} h_{i, j} \mathbf{v}_{i}\right)
$$

Secara lengkap algoritma Arnoldi Gram-Schmidt modifikasi ditulis sebagai berikut.

\section{Algoritma 1. Algoritma Arnoldi Gram-Schmidt modifikasi (GSM) [3]}

1. Diberikan nilai tebakan awal $\mathbf{x}_{0}$, hitung $\mathbf{r}_{0}=\mathbf{b}-\mathbf{A} \mathbf{x}_{0}$ dan $\mathbf{v}_{1}=\mathbf{r}_{0} /\left\|\mathbf{r}_{0}\right\|_{2}$

2. Iterasi : Untuk $j=1,2, \ldots, m$ hitung :

$$
\begin{aligned}
\mathbf{w}=\mathbf{A v}_{j} & \\
\text { Untuk } i & =1,2, \ldots, j \text { hitung } \\
h_{i, j} & =\mathbf{w} \cdot \mathbf{v}_{i} . \\
\mathbf{w} & =\mathbf{w}-h_{i, j} \mathbf{v}_{i} . \\
h_{j+1, j} & =\|\mathbf{w}\|_{2}, \quad \text { jika } h_{j+1, j}=0 \text { maka iterasi dihentikan } \\
\mathbf{v}_{j+1} & =\mathbf{w} / h_{j+1, j} .
\end{aligned}
$$

Pada tahap awal algoritma Arnoldi GSM diberikan sebarang nilai tebakan awal $\mathbf{x}_{0}$. Selanjutnya dihitung vektor basis $\mathbf{r}_{0}$ yang kemudian menjadi basis pertama subruang Krylov yaitu $\mathbf{v}_{1}$. Kemudian dibangkitkan lagi calon vektor basis yang akan mengalami proses ortogonalisasi dengan basis sebelumnya, yaitu $\mathbf{A v}_{j}$ dan didapat nilai $h_{i j}$ yang merupakan entri dari matriks Hessenberg. Kemudian terbentuk vektor yang ortogonal dengan vektor basis subruang Krylov yang sebelumnya yaitu $\mathbf{w}$. Proses berikutnya adalah menormalkan vektor $\mathbf{w}$ untuk memperoleh vektor basis subruang Krylov yang baru yaitu $\mathbf{v}_{j+1}$. Algoritma Arnoldi berhenti saat $\|\mathbf{w}\|$ sama dengan atau mendekati nol [4].

\section{METODE FULL ORTHOGONALIZATION}

Metode Full Ortogonalization merupakan salah satu metode iteratif untuk menyelesaikan sistem persamaan linear $\mathbf{A x}=\mathbf{b}$ [3]. Metode Full Orthogonalization adalah metode yang menggunakan algoritma Arnoldi. Misal diberikan nilai tebakan awal $\mathbf{x}_{0}$ dari sistem persamaan linear $\mathbf{A x}=\mathbf{b}$, pencarian solusi $\mathbf{x}_{m}$ yaitu mencari vektor $\mathbf{x}_{m} \in \mathbf{x}_{0}+\mathcal{K}_{m}\left(\mathbf{A}, \mathbf{r}_{0}\right)$ dimana $\mathbf{r}_{0}=\mathbf{b}-\mathbf{A} \mathbf{x}_{0}$ dan melihat kondisi Petrov-Galerkin yaitu:

dan $\mathbf{x}_{m} \in \mathbf{x}_{0}+\mathcal{K}_{m}\left(\mathbf{A}, \mathbf{r}_{0}\right) \Leftrightarrow \mathbf{x}_{0}+\mathbf{V}_{m} \mathbf{y}_{m}$

$$
\mathbf{r}_{m} \perp \mathcal{K}_{m}\left(\mathbf{A}, \mathbf{r}_{0}\right)
$$

Sehingga vektor residunya adalah:

$$
\mathbf{r}_{m}=\mathbf{b}-\mathbf{A} \mathbf{x}_{m}=\mathbf{r}_{0}-\mathbf{A} \mathbf{V}_{m} \mathbf{y}_{m} .
$$

Selanjutnya, berdasarkan kondisi Petrov-Galerkin, diperoleh bahwa,

Dari Persamaan (4) diperoleh,

$$
\mathbf{r}_{0} \perp \mathcal{K}_{m} \Leftrightarrow \mathbf{V}_{m}^{T} \mathbf{r}_{m}=0
$$

$$
\mathbf{V}_{m}^{T} \mathbf{r}_{0}+\mathbf{A} \mathbf{V}_{m} \mathbf{y}_{m}=0
$$

Berdasarkan algoritma Arnoldi yaitu $\mathbf{V}_{m}^{T} \mathbf{A V}_{\boldsymbol{m}}=\mathbf{H}_{m}$ sehingga diperoleh, 
atau ekuivalen dengan,

$$
\left(\mathbf{V}_{m}^{T} \mathbf{v}_{1}\right) \beta=\mathbf{H}_{m} y_{m}
$$

$$
\mathbf{H}_{m} \mathbf{y}_{m}=\beta e_{1} .
$$

Sehingga $\mathbf{y}_{m}=\mathbf{H}_{m}^{-1}\left(\beta e_{1}\right)$, dan solusi dari sistem persamaan linear ditulis menjadi $\mathbf{x}_{m}=\mathbf{x}_{0}+$ $\mathbf{V}_{m} \mathbf{H}_{m}^{-1}\left(\beta e_{1}\right)$.

Adapun algoritma Full Orthogonalization dapat dituliskan sebagai berikut:

\section{Algoritma 2. Algoritma Full Orthogonalization [3]}

1. Pilih nilai tebakan awal $\mathbf{x}_{\mathbf{0}}$, hitung $\mathbf{r}_{\mathbf{0}}=\mathbf{b}-\mathbf{A} \mathbf{x}_{\mathbf{0}}, \beta=\left\|\mathbf{r}_{0}\right\|_{2}$, dan $\mathbf{v}_{1}=\mathbf{r}_{\mathbf{0}} / \beta$

2. Iterasi : untuk $j=1,2, \ldots, m$

$$
\begin{aligned}
\mathbf{w}= & \mathbf{A} \mathbf{v}_{j} \\
\text { Untuk } i & =1,2, \ldots, j \text { hitung } \\
h_{i, j} & =\mathbf{w}_{j} \cdot \mathbf{v}_{i} \\
\mathbf{w} & =\mathbf{w}-h_{i, j} \mathbf{v}_{i} \\
h_{j+1, j} & =\|\mathbf{w}\|_{2}, \text { jika } h_{j+1, j}=0 \text { iterasi dihentikan. } \\
\mathbf{v}_{j+1} & =\mathbf{w} / h_{j+1, j} .
\end{aligned}
$$

3. Hitung $\mathbf{y}_{m}=\mathbf{H}_{m}^{-1}\left(\beta e_{1}\right)$ dan $\mathbf{x}_{m}=\mathbf{x}_{0}+\mathbf{V}_{m} \mathbf{y}_{m}$ dengan $e_{1}=[1,0, \cdots, 0]^{T}$.

Contoh 8 Selesaikan sistem persamaan linear berikut dengan metode Full Orthogonalization.

\section{Penyelesaian:}

$$
\begin{aligned}
-x_{1}-2 x_{2}+3 x_{3}+0 x_{4}+2 x_{5}+x_{6} & =2 \\
2 x_{1}+4 x_{2}-6 x_{3}+5 x_{4}+2 x_{5}+4 x_{6} & =-3 \\
x_{1}+x_{2}-x_{3}+3 x_{4}+3 x_{5}+x_{6} & =5 \\
2 x_{1}+5 x_{2}-4 x_{3}+x_{4}+5 x_{5}+x_{6} & =6 \\
-x_{2}-3 x_{3}+6 x_{4}+2 x_{5}+3 x_{6} & =4 \\
2 x_{1}-2 x_{2}-4 x_{3}+x_{4}+2 x_{5}+5 x_{6} & =-2
\end{aligned}
$$

Matriks koefisien dari sistem persamaan linear tersebut adalah sebagai berikut:

$$
\mathbf{A}=\left[\begin{array}{cccccc}
-1 & -2 & 3 & 0 & 2 & 1 \\
2 & 4 & -6 & 5 & 2 & 4 \\
1 & 1 & -1 & 3 & 3 & 1 \\
2 & 5 & -4 & 1 & 5 & 1 \\
1 & -1 & -3 & 6 & 2 & 3 \\
2 & -2 & -4 & 1 & 2 & 5
\end{array}\right] \text { dan } \mathbf{b}=\left[\begin{array}{c}
2 \\
-3 \\
5 \\
6 \\
4 \\
-2
\end{array}\right]
$$

Langkah-langkah penyelesaiannya adalah sebagai berikut:

1. Nilai tebakan awal yang dipilih adalah $\mathbf{x}_{0}=\left[\begin{array}{llllll}1 & 0 & 0 & 0 & 0 & 0\end{array}\right]^{T}$

Kemudian dihitung $\mathbf{r}_{0}, \beta$ dan $\mathbf{v}_{1}$,

$$
\begin{aligned}
\mathbf{r}_{0} & =\mathbf{b}-\mathbf{A} \mathbf{x}_{0}=\left[\begin{array}{llllll}
2 & -3 & 5 & 6 & 4 & -2
\end{array}\right]^{T}-\left[\begin{array}{lllllll}
-1 & 2 & 1 & 2 & 1 & 2
\end{array}\right]^{T} \\
& =\left[\begin{array}{lllllll}
3 & -5 & 4 & 4 & 3 & -4
\end{array}\right]^{T} \\
\beta & =\left\|\mathbf{r}_{0}\right\|_{2}=9,5394 \\
\mathbf{v}_{1} & =\left[\begin{array}{llllll}
0,3145 & -0,5241 & 0,4193 & 0,4193 & 0,3145 & -0,4193
\end{array}\right]^{T}
\end{aligned}
$$

2. Iterasi : untuk $j=1,2, \ldots, 6$

a. Iterasi $1(j=1)$

Untuk $i=1$

$$
\mathbf{w}=\mathbf{A v}_{1}=\left[\begin{array}{llllll}
2,2013 & -2,9349 & 1,1532 & -2,0962 & 1,4676 & -1,0482
\end{array}\right]^{T}
$$




$$
\begin{aligned}
h_{11}= & \mathbf{w} \cdot \mathbf{v}_{1}=2,7362 \\
\mathbf{w} & =\mathbf{w}-h_{11} \mathbf{v}_{1}=\left[\begin{array}{llllll}
1,3408 & -1,5009 & 0,0059 & -3,2435 & 0,6071 & 0,0991
\end{array}\right]^{T} \\
h_{21}= & \|\mathbf{w}\|_{2}=3,8664 \\
& \mathbf{v}_{2}=\left[\begin{array}{llllll}
0,3468 & -0,3882 & 0,0015 & -0,8389 & 0,1570 & 0,0256
\end{array}\right]^{T}
\end{aligned}
$$

b. Iterasi $2(j=2)$

$$
\mathbf{w}=\mathbf{A v}_{2}=\left[\begin{array}{llllll}
0,7737 & -4,6463 & -2,0630 & -1,2817 & -3,9121 & 1,0671
\end{array}\right]^{T}
$$

Untuk $i=1$

$$
\begin{aligned}
h_{12} & =\mathbf{w} \cdot \mathbf{v}_{1}=-0,4018 \\
h_{12} \mathbf{v}_{1} & =\left[\begin{array}{llllll}
-0,1264 & 0,2016 & -0,1685 & -0,1685 & -0,1264 & 0,1685
\end{array}\right]^{T} \\
\mathbf{w} & =\mathbf{w}-h_{12} \mathbf{v}_{1} \\
& =\left[\begin{array}{llllll}
0,9001 & -4,8569 & -1,8945 & -1,1132 & -3,7857 & 0,8986
\end{array}\right]^{T}
\end{aligned}
$$

\begin{tabular}{|c|c|c|}
\hline iterasi & $i=1,2, \ldots, 6$ & $h_{i j}$ \\
\hline \multirow{3}{*}{$j=3$} & $i=1$ & $-3,0914$ \\
\hline & $i=2$ & 4,4348 \\
\hline & $i=3$ & $-0,7356$ \\
\hline \multirow{4}{*}{$j=4$} & $i=1$ & 0,5121 \\
\hline & $i=2$ & $-0,0959$ \\
\hline & $i=3$ & $-2,6138$ \\
\hline & $i=4$ & 0,4831 \\
\hline \multirow{5}{*}{$j=5$} & $i=1$ & $-1,1452$ \\
\hline & $i=2$ & $-2,9105$ \\
\hline & $i=3$ & $-5,8618$ \\
\hline & $i=4$ & 0,6755 \\
\hline & $i=5$ & 6,3064 \\
\hline \multirow{6}{*}{$j=6$} & $i=1$ & 1,1122 \\
\hline & $i=2$ & 7,7276 \\
\hline & $i=3$ & 5,7776 \\
\hline & $i=4$ & $-1,5993$ \\
\hline & $i=5$ & $-3,7229$ \\
\hline & $i=6$ & $-1,3474$ \\
\hline
\end{tabular}

Untuk $i=2$

$$
\begin{aligned}
h_{22} & =\mathbf{w} \cdot \mathbf{v}_{2}=2,5573 \\
h_{22} \mathbf{v}_{2} & =\left[\begin{array}{lllllll}
0,8869 & -0,9927 & 0,0038 & -2,1453 & 0,4015 & 0,0655
\end{array}\right]^{T} \\
\mathbf{w} & =\mathbf{w}-h_{22} \cdot \mathbf{v}_{2}=\left[\begin{array}{llllll}
0,0132 & -3,8642 & -1,8983 & 1,0321 & -4,1872 & 0,8331
\end{array}\right]^{T} \\
h_{32} & =\left[\begin{array}{llllll}
\|\mathbf{w}\|_{2}=6,1504 \\
\mathbf{v}_{3}=\frac{\mathbf{w}}{h_{32}}
\end{array}=\left[\begin{array}{llllll}
0,0021 & -0,6283 & -0,3086 & 0,1678 & -0,6808 & 0,1354
\end{array}\right]^{T}\right.
\end{aligned}
$$

Untuk langkah selanjutnya sampai iterasi ke-6 disajikan dalam Tabel 1.

Tabel 1. Entri matriks Hessenberg untuk $j=3,4,5,6$ 
Sehingga diperoleh matriks Hessenberg,

$$
\mathbf{H}_{6}=\left[\begin{array}{cccccc}
2,7362 & -0,4018 & -3,0914 & 0,5121 & -1,1452 & 1,1122 \\
3,8664 & 2,5573 & 4,4348 & -0,0959 & -2,9105 & 7,7276 \\
0 & 6,1504 & -0,7356 & -2,6138 & -5,8618 & 5,7776 \\
0 & 0 & 2,4384 & 0,4831 & 0,6755 & -1,5993 \\
0 & 0 & 0 & 4,5252 & 6,3064 & -3,7229 \\
0 & 0 & 0 & 0 & 0,6964 & -1,3474
\end{array}\right] .
$$

dan matriks ortogonal,

$$
\mathbf{V}_{\mathbf{6}}=\left[\begin{array}{cccccc}
0,3145 & 0,3468 & 0,0021 & -0,5995 & 0,4827 & -0,4342 \\
-0,5241 & -0,3882 & -0,6283 & -0,4098 & 0,0174 & -0,1077 \\
0,4193 & 0,0015 & -0,3086 & -0,2701 & 0,1133 & 0,8020 \\
0,4193 & -0,8389 & 0,1678 & 0,0558 & 0,2461 & -0,1689 \\
0,3145 & 0,1570 & -0,6808 & 0,5670 & 0,1574 & -0,2579 \\
-0,4193 & 0,0256 & 0,1354 & 0,2741 & 0,8176 & 0,2486
\end{array}\right] .
$$

Selanjutnya akan ditentukan invers dari matriks $\mathbf{H}_{6}$ menggunakan metode Gauss-Jordan, sehingga diperoleh matriks invers,

$$
\mathbf{H}_{6}^{-1}=\left[\begin{array}{cccccc}
0,1777 & 0,1328 & -0,0436 & -0,0294 & -0,0393 & 0,8652 \\
-0,0235 & 0,0166 & 0,1541 & -0,0136 & 0,0935 & 0,4948 \\
-0,0691 & 0,0489 & -0,0249 & 0,2259 & -0,0296 & -0,0694 \\
0,2638 & -0,1867 & 0,0948 & 0,7026 & 0,1669 & -1,7414 \\
-0,2724 & 0,1928 & -0,0979 & -0,7255 & 0,0558 & 1,1677 \\
-0,1408 & 0,0996 & -0,0506 & -0,3750 & 0,0288 & -0,1386
\end{array}\right] .
$$

3. Penentuan $\mathbf{y}_{6}=\mathbf{H}_{6}^{-1}\left(\beta e_{1}\right)$ dan $\mathbf{x}_{6}=\mathbf{x}_{0}+\mathbf{V}_{6} \mathbf{y}_{6}$ dengan $e_{1}=[1,0, \cdots, 0]^{T}$.

$$
=\left[\begin{array}{cccccc}
0,1777 & 0,1328 & -0,0436 & -0,0294 & -0,0393 & 0,8652 \\
-0,0235 & 0,0166 & 0,1541 & -0,0136 & 0,0935 & 0,4948 \\
-0,0691 & 0,0489 & -0,0249 & 0,2259 & -0,0296 & -0,0694 \\
0,2638 & -0,1867 & 0,0948 & 0,7026 & 0,1669 & -1,7414 \\
-0,2724 & 0,1928 & -0,0979 & -0,7255 & 0,0558 & 1,1677 \\
-0,1408 & 0,0996 & -0,0506 & -0,3750 & 0,0288 & -0,1386
\end{array}\right]\left(9,5394\left[\begin{array}{l}
1 \\
0 \\
0 \\
0 \\
0 \\
0
\end{array}\right]\right)=\left[\begin{array}{c}
1,6956 \\
-0,2244 \\
-0,6596 \\
2,5164 \\
-2,5985 \\
-1,3430
\end{array}\right] \text {, }
$$

Sehingga $\mathbf{x}_{6}$,

$$
=\left[\begin{array}{l}
1 \\
0 \\
0 \\
0 \\
0 \\
0
\end{array}\right]+\left[\begin{array}{cccccc}
0,3145 & 0,3468 & 0,0021 & -0,5995 & 0,4827 & -0,4342 \\
-0,5241 & -0,3882 & -0,6283 & -0,4098 & 0,0174 & -0,1077 \\
0,4193 & 0,0015 & -0,3086 & -0,2701 & 0,1133 & 0,8020 \\
0,4193 & -0,8389 & 0,1678 & 0,0558 & 0,2461 & -0,1689 \\
0,3145 & 0,1570 & -0,6808 & 0,5670 & 0,1574 & -0,2579 \\
-0,4193 & 0,0256 & 0,1354 & 0,2741 & 0,8176 & 0,2486
\end{array}\right]\left[\begin{array}{c}
1,6956 \\
-0,2244 \\
-0,6596 \\
2,5164 \\
-2,5985 \\
-1,3430
\end{array}\right]=\left[\begin{array}{c}
-0,7256 \\
-1,3189 \\
-1,1369 \\
0,5162 \\
2,3112 \\
-2,5746
\end{array}\right]
$$

Sehingga diperoleh solusi dari SPL adalah $x_{1}=-0,7256, x_{2}=-1,3189, x_{3}=-1,1369, x_{4}=$ $0,5162, x_{5}=2,3112$ dan $x_{6}=-2,5746$.

\section{PENUTUP}

Terdapat dua tahapan dalam menyelesaikan sistem persamaan linear dengan Metode Full Orthogonalization, tahap pertama adalah penentuan basis subruang Krylov $\mathcal{K}_{m}$ dan tahap kedua adalah penentuan solusi. Tahap penentuan basis subruang Krylov menggunakan algoritma Arnoldi yang mereduksi matriks koefisien dari sistem persamaan linear menjadi matriks Hessenberg sehingga matriks $\mathbf{A}$ dapat ditulis sebagai $\mathbf{A}=\mathbf{V}_{m} \mathbf{H}_{m} \mathbf{V}_{m}^{T}$, dengan $\mathbf{V}_{m}$ matriks ortogonal. Pada tahap penentuan solusi metode Full Orthogonalization untuk memperoleh vektor $\mathbf{y}_{m}$ membutuhkan invers dari matriks Hessenberg yang dicari dengan eliminasi Gauss-Jordan. Solusi pendekatan SPL adalah $\mathbf{x}_{m}=\mathbf{x}_{0}+$ $\mathbf{V}_{m} \mathbf{y}_{m}$. 


\section{DAFTAR PUSTAKA}

[1]. Leon SJ. Aljabar Linear dan Aplikasinya, Edisi ke-5. Jakarta: Erlangga; 2001.

[2]. Golub GH, Loan CV. Matrix Computation, Fourth Edition. Baltimore: The John Hopkins University Press; 2013.

[3]. Saad Y. Iterative Method for Sparse Linear System, Second Edition. London: Siam; 2000.

[4]. Meyer CD. Matrix Analysis and Applied Linear Algebra. London: Siam; 2001.

[5]. Mohd IB, Mamat MB, Dasril YB, Ismail F, Farikhin. Nilai Solusi Pendekatan Sistem Linear Skala Besar Menggunakan GMRES. Semarang: Jurusan Matematika Fakultas Matematika dan Ilmu Pengetahuan Alam UNDIP; 2008.

SEPLIONG

YUNDARI

FRANSISKUS FRAN
: Jurusan Matematika, FMIPA UNTAN, Pontianak sepliong94@gmail.com

: Jurusan Matematika, FMIPA UNTAN, Pontianak yundari@math.untan.ac.id

: Jurusan Matematika, FMIPA UNTAN, Pontianak fransiskusfran@math.untan.ac.id 